\title{
A STUDY OF PSYCHIATRIC MORBIDTY AMONGST CHILDREN ATTENDING A CHILD GUIDANCE CLINIC AT A TERTIARY LEVEL TEACHING HOSPITAL IN NEPAL
}

\author{
Manisha Chapagai, Kabin Man dangol and Pratiksha Tulachan
}

\begin{abstract}
:
Background: Mental health and its related problems are growing concerns over the world. The early onset of emotional and behavioral problem in the young children is related to a variety of health and behavior problems in adolescence. It is a challenging all over the world to determine the epidemiology of childhood mental disorders.
\end{abstract}

Objective: The aim of this study is to sort out the prevalence and predominance of mental illness and their onset of age and sex among the child and adolescent who attended in the child guidance clinic in TUTH.

Methodology: A retrospective study of a total of 539 consecutive cases of child and adolescent attended in Child Guidance Clinic TUTH. Diagnosis was made according to the criteria of Diagnostic and Statistical Manual of Mental Disorders, 4th edition, Text Revision.

Result: The cases from the age of 0.4 year to 21 years with mean age $8.85 \pm 4.08$ years. Significantly majority were boys $(n=343,63.6 \%)$ and most of from out of the Kathmandu valley $(n=300,53.2 \%)$. Significantly most case referred from ENT OPD of TUTH $(n=97,18 \%)$ and mental retardation was the commonest $(n=81,15 \%)$ followed by conversion disorder $(n=77$, $14.3 \%)$ and anxiety spectrum disorder $(n=63,11.7 \%)$

Conclusion: Boys are common in mental illness among child and adolescents. The common diagnoses among child and adolescent are mental retardation, conversion disorder, anxiety spectrum disorders and Autism spectrum disorder.

Key words: $\quad$ Mental illness, Child Guidance Clinic, mental retardation, ENT OPD, TUTH

\section{Introduction}

Mental health in child and adolescent is an essential component of overall health and its importance is being recognized. Many studies have shown increasing a large number of young people being disabled from mental illness in the worldwide.

A comprehensive review study of child psychiatric epidemiology in community surveys noted that the number of children and adolescents has risen from 10000 in studies published between 1980 and 1993 to nearly $4000 \mathrm{p} 0$ from 21 studies published between 1993 and 2002. The results of these studies indicate that about one out of every three to four youths is estimated to meet lifetime criteria for a Diagnostic and Statistical Manual of Mental Disorders (DSM). $\underline{1}, \underline{2}$

The World Health Organization (WHO) reported that $20 \%$ of children and adolescents suffer from different types of mental illness 
worldwide $\underline{3}$ and, suicide is supposed as major cause of death among adolescents up to $50 \%$ of all adult mental disorders have their onset in adolescence. 4 Similarly, the U.S. Department of Health and Human Services' (DHHS') report estimated that at least one in five $(20 \%)$ children and adolescents has a mental health disorder at some point in their life from childhood to adolescence and at least one in $10(10 \%)$, or about 6 million people, has a serious emotional disturbance at some point in their life. $\underline{5}$

The first three years of children life is for school readiness, however emotional health plays an important role in preparing children to engage in cognitive tasks. $\underline{6}, \underline{7}$ Before thought and language, the emotion, it is this early affect within the context of the earliest relationships that forms the basis for all future development. $\underline{8}, \underline{9}$ Research has also shown that the emergence of early onset emotional/behavioral problems in young children is related to a variety of health and behavior problems in adolescence. $\underline{10}, \underline{11}$

Studies reveal that the risk factors for the development of mental disorders in children have been considered mainly into two perspectives: child characteristics and those of his/her parents/family. Child characteristics include gender, age, ethnicity, physical health, cognitive and psychological function, pre- and perinatal exposures to illness, physical stress, alcohol, drugs, nutrition, infections and other environmental agents, and lifetime history of environmental exposures to toxins, stress, infections, social environment and stressful life events. Family and parent characteristics include parental education, age, social class, employment, psychiatric and medical history, and family function, structure. $\underline{12}, \underline{13}, \underline{14}, \underline{15}$ One of the most, consistent and potent risk factors for the development of mental disorders in children is a parental history of mental disorders.
A results of a recent 3-year follow-up of the UK study of child health found that different risk factors predicted the onset and the persistence of mental and behavior disorders in youth.16 The onset of emotional disorders was predicted by physical illness, changes in the number of parents in the home, the number of children at home and poor maternal mental health. Predictors of conduct disorder onset included low income, rented accommodations, low maternal education, living in a reconstituted family, special educational needs of the child and changes in maternal mental health over time. Accumulation of stressful life events predicted the onset of either type of disorder. Persistence of mental disorders in general was predicted by poor maternal mental health, low socioeconomic status, and rented accommodations. 16

In an epidemiology of child psychiatry disorders from different study reviews reveals that mental retardation, neurosis, emotional and behavioral disorders and epilepsy formed the major groups of disorders.17, $\underline{18} \mathrm{~A}$ different studies in India have revealed that the prevalence rates of the child morbidity was of $12.5 \%$ in $0-16 \mathrm{yrs}$ in one community sample study, 9.4\% in 8-12 yrs olds in another group community sample. Similarly $6.3 \%$ in 4-11 yrs old school in children sample study $\underline{19}, \underline{20}$

In Nepal, a survey was conducted and found that children accounted for 8\% (105) of total patients and majority was suffering from mental retardation followed by neurosis and epilepsy. 21 In another study that majority of children attending the psychiatric OPD were suffering from epilepsy. 22 Similarly in another study the children with psychiatric morbidity were of $3.34 \%$ of the total outpatient population and more than half were suffering from mental retardation. In another study $31.75 \%$ were suffering from behavioral and emotional disorder. $\underline{23} \underline{24} . \underline{25}$ 
Determining the epidemiology of childhood mental disorders is a challenge throughout the world. The definition or recognition of disorder varies or has variable interpretations and the cultural component of what constitutes a disorder is only now being more fully appreciated by epidemiologist and researchers. In studying the epidemiology of psychiatric disorder in children and adolescents in developing and developed countries, it is important to define not only the prevalence and incidence of the disorders but also the associated burden of disease as measured in terms of cost of care over the lifespan and lost human potential. It must be recognized that the impairment associated with disorder may vary in different cultures $\underline{26}$

\section{Materials and Method}

\section{Study method}

Patients, who were recorded as new case, during the period in between 14th April 2010 to 18th Dec 2011, were included in the study.The detail demographics and diagnosis was obtained. Diagnoses were made according to DSM-IV TR diagnostic criteria..

\section{Data analysis}

The data were analyzed using the Statistical package for the social science version 12 for Windows. Descriptive statistic for all demographic and clinical variables is used in the logistics as following tables.

\section{Results}

Five hundred thirty nine participants were assessed for prevalence of psychiatric morbidity in child and adolescents. Four hundred eighty eight participants met criteria DSM-IV TR psychiatric morbidity diagnosis. Demographic variable with the data were listed in Table 1. The mean age of participants was 8.85 years $(\mathrm{SD}=4.08) ; 64 \%(n=539)$ of the sample were boys and $56 \%(n=539)$ were of out of the valley (Figure 2); 50.1\% $(n=539)$ were age group of 10-19 years.

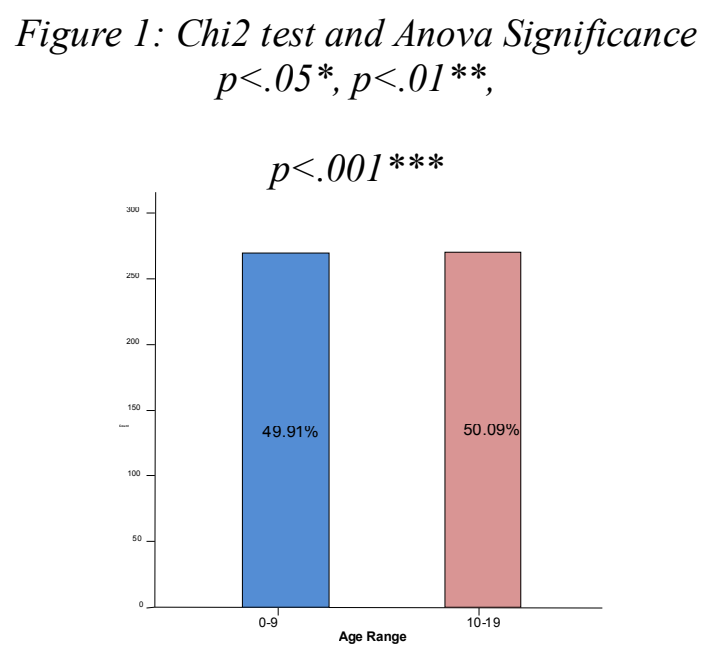

The number of cases of age group 0-9 did not differ significantly from the cases of 10-19 age groups. In the Area, the numbers of case among three group was differ significantly $(p=.000)$. Similarly, the mean age of participant in among three area groups was differ significantly (shown in Table $1 p=.013$ ). The number of cases $(63.6 \%)$ in boy group was differ significantly from the number of cases $(36.4 \%)(p=.000)$

In terms of referral, $18.0 \%(n=97)$ cases were referred from ENT OPD and $16.7 \%(n=90)$ cases were from Pediatric OPD of the hospital. The Kanti Children Hospital referred the cases about $11 \%(n=60)$. About $20.2 \%$ $(n=109)$ cases came to the clinic by self. About $15.6 \%(n=84)$ cases didn't have any record in the referral. The referral from different OPD and hospital was differ significantly $(p=.000)$ (Table 2$)$

In an educational level, about 309 cases reported of their attendance in schooling, and among them $16.2 \% \quad(n=50)$ cases were in Primary level and $2.9 \%(n=9)$ in grade X. Table 3 shows that the cases in different level of education were significantly different $(p=.001)$ 
Figure 2: Distribution of cases according to geographical location

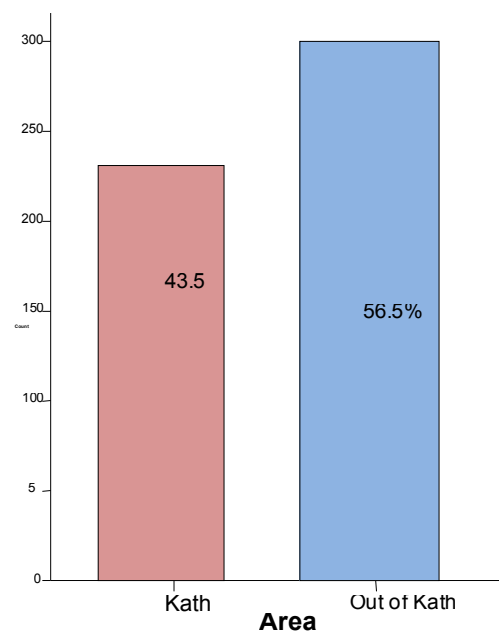

Table 2: Distribution of cases according to pattern of referral

\begin{tabular}{|c|c|c|c|}
\hline Referral & $\begin{array}{c}\text { cases } \\
(n=539)\end{array}$ & $\%$ & $\begin{array}{c}\mathbf{D}^{2}- \\
\text { value/ } \\
\mathrm{df} / p- \\
\text { value }\end{array}$ \\
\hline Psychiatric OPD & 15 & 2.8 & \multirow{10}{*}{$\begin{array}{c}329.510 \\
10 \\
.000 * * *\end{array}$} \\
\hline Pediatric OPD & 90 & 16.7 & \\
\hline Medical OPD & 33 & 6.1 & \\
\hline ENT OPD & 97 & 18.0 & \\
\hline Other OPD & 12 & 2.2 & \\
\hline $\mathrm{KCH}$ & 60 & 11.1 & \\
\hline $\begin{array}{c}\text { Dhulikhel } \\
\text { Hospital }\end{array}$ & 2 & 0.4 & \\
\hline Army Hospital & 5 & 0.9 & \\
\hline Self & 109 & 20.2 & \\
\hline Other & 84 & 15.6 & \\
\hline
\end{tabular}

$* * * p<0.001$

During the period of the study, the cases of mental retardation were found very high $15.0 \%(n=81)$ and which was followed by the conversion disorder $14.3 \%(n=77)$ which also included the cases of psychogenic vomiting
(Table 4). Similarly the cases of anxiety disorder was also found higher $11.7(n=63)$ in visiting the clinic during the study period which also included the cases of school refusal and school phobia.

The cases of seizure disorder were also found high $7.1 \%(n=38)$ in visiting the clinic. The cases of Hearing Impairment $7.8 \% \quad(n=42)$ were in visiting the clinic referred from ENT due to speech delay caused by hearing impairment. The variance in case distribution in the disorders was found significant $(p=.001$.

In terms of sex and childhood disorder, in most of the cases the disorders were found higher in boys than in girls though there was no difference significantly $(p=.081)$. However in childhood depression the cases were much in girls than boys.

\section{Discussion}

In this study, the most of the cases were associated with boys which is difference significantly and prevalence of the cases in childhood illness were mostly mental retardation, anxiety disorder, conversion disorder and speech delayed with or without hearing loss. The distribution of age variance in this study between the age group 0-9 \& 1019 was approximately similar. However, baseline and the mean age of the disorder group was 8.86 years $(\mathrm{SD}=4.08)$. We had the cases coming from resident of the Kath valley and out of the valley and relatively more from the out of the valley. This finding was consistent with fact that the hospital is tertiary setting and the largest one in the country in terms of equipments and human resources.

Forty three percent of the total subjects were advised to consult a psychiatric service by other department of the institute (Pediatric, ENT, and Internal Medicine); about twelve percent were referred in the clinic by other hospitals (mainly Kanti Children Hospital, 
Dhulikhel Hospital and army hospital). Twenty percent were by self however about $15 \%$ were by other Sources e.g. friends, relative, neighbors, other patients, traditional healer and even the media. The high numbers of cases were of grade five $(13.6 \%)$. However, the cases were also high from other grade levels $(11 \%$ grade seven $10 \%$ in grade three and four).

The prevalence of different psychiatric disorders were consistent with the diagnostic profile of the study showing disorder usually first diagnosed in infancy, childhood or adolescence; anxiety spectrum, somatoform, and seizure disorders as main diagnosed. We had the predominance of Mental Retarded cases, followed by conversion disorder and anxiety spectrum disorder and seizure disorder as well. About 3\% cases were diagnosed of ADHD and $1.9 \%$ cases were with co-morbid. The finding of predominance of mental retardation, seizure disorder and low cases of ADHD is consistent with the study in India and Nepal. The high prevalence of mental retardation $(15 \%)$ in the study may due to the large number of cases referred from ENT and Pediatric OPD of the institute and Kanti Children Hosptial which is very close distant to the institute and easier to refer in this setting for Intelligence assessment to those subjects who develops poor communication hearing impairment as well as who have behavior problem with poor academic performance. Similar high prevalence of mental retardation has also been reported by various study in children and adolescent mental health in Nepal in different period, 21, 23, $27^{27}$ and other different studies in different areas of India. $\underline{18}, \underline{28}, \underline{20}$ The mental retardation is also second common diagnosis (16.2\%) in another study in India.29 Somatoform disorder, mainly the conversion disorder was found the second major disorder in this study which may be due to the clinic is special for child and there were many cases referred for evaluation of seizure disorder or conversion disorder from different settings and hospitals. Moreover culturally, girls are perceived as weak person and have less opportunity to express their feeling and stress verbally then consequently the psychological stresses come out in physical symptoms. The finding of high prevalence of somatoform disorder in this study is similar to the finding of various studies in Nepal 27, $\underline{22}, \underline{25}$

The diagnosis of anxiety disorder is third $(11.7 \%)$ predominance disorder which is also common diagnosis in study of general adult psychiatric clinic setting in Eastern Nepal. 30 Male is predominance in the diagnosis of most disorders in this study which was similar to the different studies in Nepal and India, 27, 29, 30

\section{Conclusion}

Mental retardation is the most commonly diagnosed in our setting of Child guidance clinic may be due to considering only the measuring of academic performance and IQ finding but usually overlooking the patients' adaptive functioning. The most disorders are male dominant and conversion and anxiety disorders are very common in diagnosis in the child and Adolescents cases.

Acknowledgement : The authors would like to expresses sincere thanks to Child Psychiatrist Dr. AR Kunwar, all residents of Department of Psychiatry and Mental health TUTH.

Limitation of this Study: Since this study was done in Child guidance Clinic of the hospital and most of diagnosis was made based on the first history taking by the residents. No supplementary tools were used.

\section{Reference}

1. Costello EJ., Mustillo S., Keller G., Angold A. Prevalence of psychiatric disorders in childhood and adolescence. In: Levin BL, Petrila J, Hennessy KD, eds. Mental Health Services: a Public Health Perspective, Second Edition. Oxford, UK: Oxford University Press; 2004:111-128. 
2. Costello E., Egger H., Angold A. 10-year research update review: the epidemiology of child and adolescent psychiatric disorders: I. Methods and public health burden. J Am Acad Child Adol Psychiatry. 2005; 44: 972-986.

3. WHO The World Helath Report 2000- Health Systems: Improving performance, Geneva: World Health Organization ;2000

4. WHO. Mental Health: New Understanding, New hope. The World Health Report. Geneva: World Health Organization;2001

5. US Department of Health and Human Services. Mental Health: A Report of the Surgeon General Rockville, MD; 1999

6. Beckwith L, Cohen SE. Maternal responsiveness with preterm infants and later competency. New Dir Child Dev. 1989;43:75-87

7. Thompson RA. Handbook of attachment: theory, research, and clinical applications. New York: Guilford Press; 1999. Early attachment and later development. In: Cassidy J and Shaver PR, editors; pp. 265-286.

8. Ainsworth MDS. The development of motherinfant attachment. In: Caldwell BM, Ricciuti HN, editors. Review of child development research. Vol. 3. Chicago: University of Chicago Press; 1973. pp. 1-94.

9. Winnicott DW. The maturational process and the facilitating environment. New York: International Universities Press; 1965.

10. Campbell SB. Longitudinal studies of active and aggressive preschoolers: individual differences in early behavior and outcome. In: Cicchetti D, Toth SL, editors. Internalizing and externalising expressions of dysfunction: Rochester symposium on developmental psychopathology. Vol. 2. Hillsdale (NJ): Erlbaum; 1991. pp. 57-90.

11. Ramey CT, Ramey SL. Early intervention and early experience. Am Psychol. 1998; 53:109-120.

12. Earls F. Epidemiology and child psychiatry: future prospects. Compr Psychiatry. 1982; 23:7584.

13. Brauner CB., Stephens CB. Estimating the prevalence of early childhood serious emotional/behavioral disorders: challenges and recommendations. Public Health Rep. 2006; 121: 303-310.
14. Fergusson DM.., Norwood U. The Christchurch Health and Development Study: review of findings on child and adolescent mental health. AustNZ J Psychiatry. 2001; 35:287-296.

15. Goodman SH., Hoven CW., Narrow WE., et al. Measurement of risk for mental disorders and competence in a psychiatric epidemiologic community survey: the National Institute of Mental Health Methods for the Epidemiology of Child and Adolescent Mental Disorders (MECA) Study. Soc Psychiatry Psychiatr Epidemiol. 1998;33:162-173

16. Parry-Langdon N., Clements A., Fletcher D., Goodman R. Three Years On: Survey Of the Development and Emotional Weil-Being of Children and Young People. Newport, UK: Office for National Statistics; 2008

17. Chadd R.K., Psychiatrifc Morbidity in Preschool children: A clinical Based Study Indian J Pediatr 1995; 62:77-81

18. Chaudhary S., Prasad PL., Zacharias R., Madhusudan T., Saini R. Psychiatric Morbidity Pattern in a Child Guidance Clinic MJAFI 2007; $63(2)$

19. Srinath S., Girimaji S.C., Gururaj G., Seshadri S, Subbakrishan D.K., Bhola P. et. al. Epidemiological study of child and adolescent psychiatric disorders in Urban and rural areas of Bangalore, India. Indian J Med Res 2005; 122: 6779

20. Malhotra S., Kohli A., Arun P. Prevalence of psychiatric disorder in school children in India. Indian J Med Res 2002;116:21-8

21. Shrestha DM. Neuro psychiatric problems in children attending a general psychiatric Clinic in Nepal. Nepal Pediartic Society Journal 1986; 5; 97-101

22. Nepal MK, Sharma P, Gurung CK. the first child Psychiateic Clinic and: an initial appraisal. NEPAS 1988;7(1):71-5

23. Regmi SK, Khalid A, Nepal MK, Poharel A. A Study of Sociodemographic Charactidscs and diagnoseic profile in psychiatric outpatients. Nepalese Journal of Psychiatry 1999;1(1) 26-33

24. Regmi S.K., Nepal M. K., Khalid A., Sinha U.K., Kkiljunen R, Pokharel A et.al. A study of children and adolescents attending the child guidance clinic of a general hospital. Nepalese Journal of psychiatry 2000; 1 (2): 90-7 
25. Pokharel A, Ojha SP, Koirala NR, Regmi SK, Pradhan SN, Sharma VD et.al. A profile of Children and Adolescents referred by pediatricians to the child guidance clinic of Tribhuvan Teaching Hospital. Nepalese Journal of Psychiatry 2001; 2: $116-22$

26. Belfer M.L. Child and adolescent mental health around the world challenges for progress JIACAM $1: 1 ;(3) 1-6$

27. Tulachan P, Chapagain M, Kunwar AR, Sharma VD. Psychiatric Morbidity Pattern in Child and Adolescent Guidance Clinic. J
Psychiatric Association of Nepal Vol. 1, No. 1, 2011

28. Sidana A. Bhatia MS, Chaudhary S. Prevalence and Pattern of Psychiatric Morbidity in Children. Indian J. Med Science 1998 Dec; 52(12): 556-8

29. Banarjee T. Psychiatric Morbidity among rural primary School children in West Bengal. Indian J Psychiat., 1997; 39(2) 130-135

30. Shakya D.R. Psychiatric Morbidity Profiles of Child and Adolescent Psychiatry Out-Patients in a Tertiary -Care Hospital. J Nepal Paediatr. Soc. May-August 2010; 30 (2) 79-84

Address of correspondence: Manisha Chapagai, Assistant professor, Department of Psychiatry and Mental health, Institute of Medicine,Email * Corresponding author: manisha_chapagai@yahoo.com, kmdangol@gmail.com 
Table 1: Distribution of cases according age group and gender

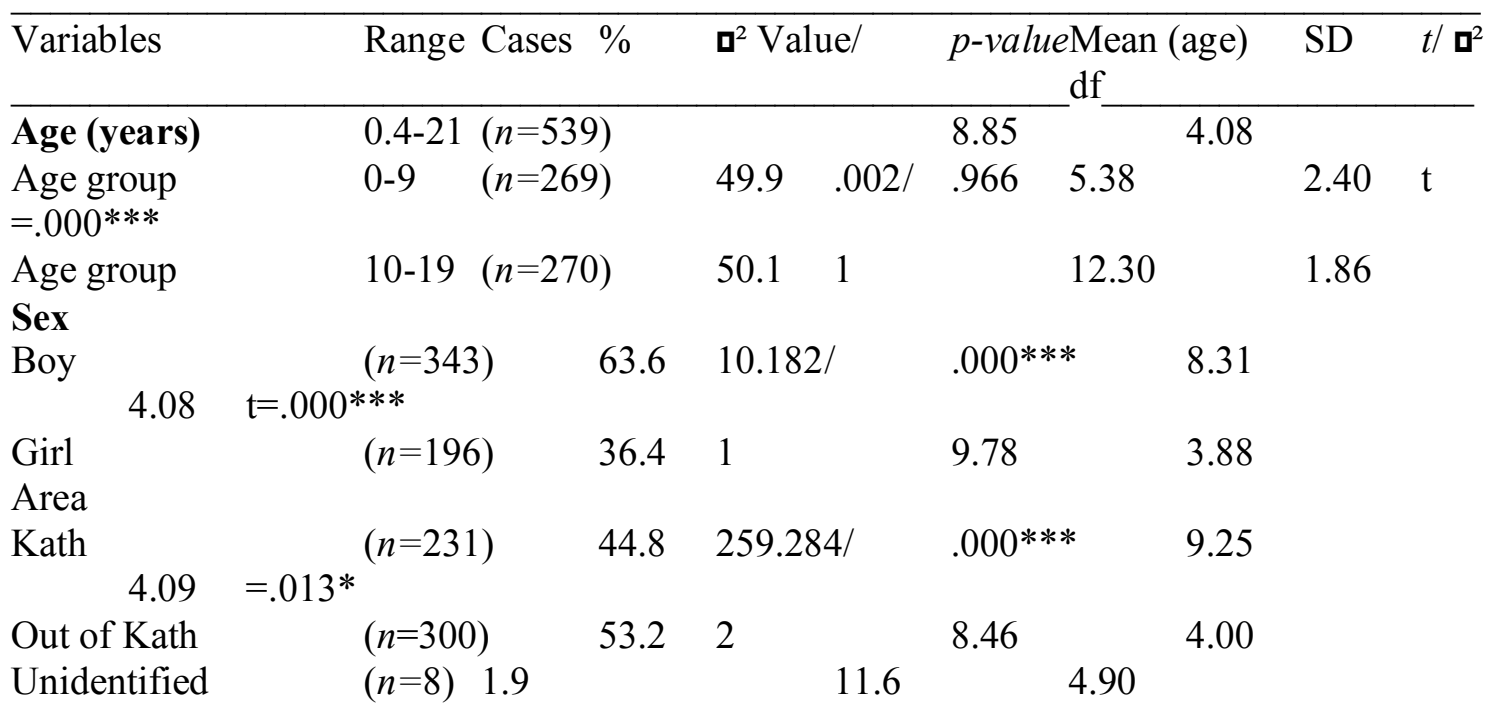

Figure 1: Chi2 test and Anova Significance $p<.05^{*}, p<.01^{* *}, p<.001^{* * *}$

Table 3: Distribution of cases according to level of education

\begin{tabular}{|c|c|c|c|c|c|c|c|}
\hline Education & $\begin{array}{c}\text { Cases } \\
(n=309)\end{array}$ & $\%$ & $\begin{array}{c}\text { mean } \\
\text { age }\end{array}$ & Std & SEm & $\begin{array}{c}\mathbf{D}^{2}- \\
\text { value } \\
\text { df }\end{array}$ & $\begin{array}{c}p \text { - } \\
\text { value }\end{array}$ \\
\hline Primary level & 50 & 16.2 & 6.66 & 2.49 & .35 & \multirow{11}{*}{$\begin{array}{c}52.220 \\
10\end{array}$} & \multirow{11}{*}{$.000 * *$} \\
\hline grade I & 27 & 8.7 & 7.67 & 1.90 & .37 & & \\
\hline II & 25 & 8.1 & 9.40 & 2.04 & .40 & & \\
\hline III & 32 & 10.4 & 9.84 & 1.83 & .32 & & \\
\hline IV & 33 & 10.7 & 10.30 & 1.33 & .23 & & \\
\hline $\mathrm{V}$ & 42 & 13.6 & 11.60 & 1.82 & .28 & & \\
\hline VI & 25 & 8.1 & 12.20 & 1.08 & .21 & & \\
\hline VII & 35 & 11.3 & 13.09 & 1.54 & .26 & & \\
\hline VIII & 14 & 4.5 & 13.21 & .89 & .24 & & \\
\hline IX & 17 & 5.5 & 13.88 & 1.05 & .26 & & \\
\hline $\mathrm{X}$ & 9 & 2.9 & 15.67 & 1.50 & .50 & & \\
\hline
\end{tabular}


Table 4: Prevalence of childhood psychiatric disorder and cases of boys and girl with the Chi-Square

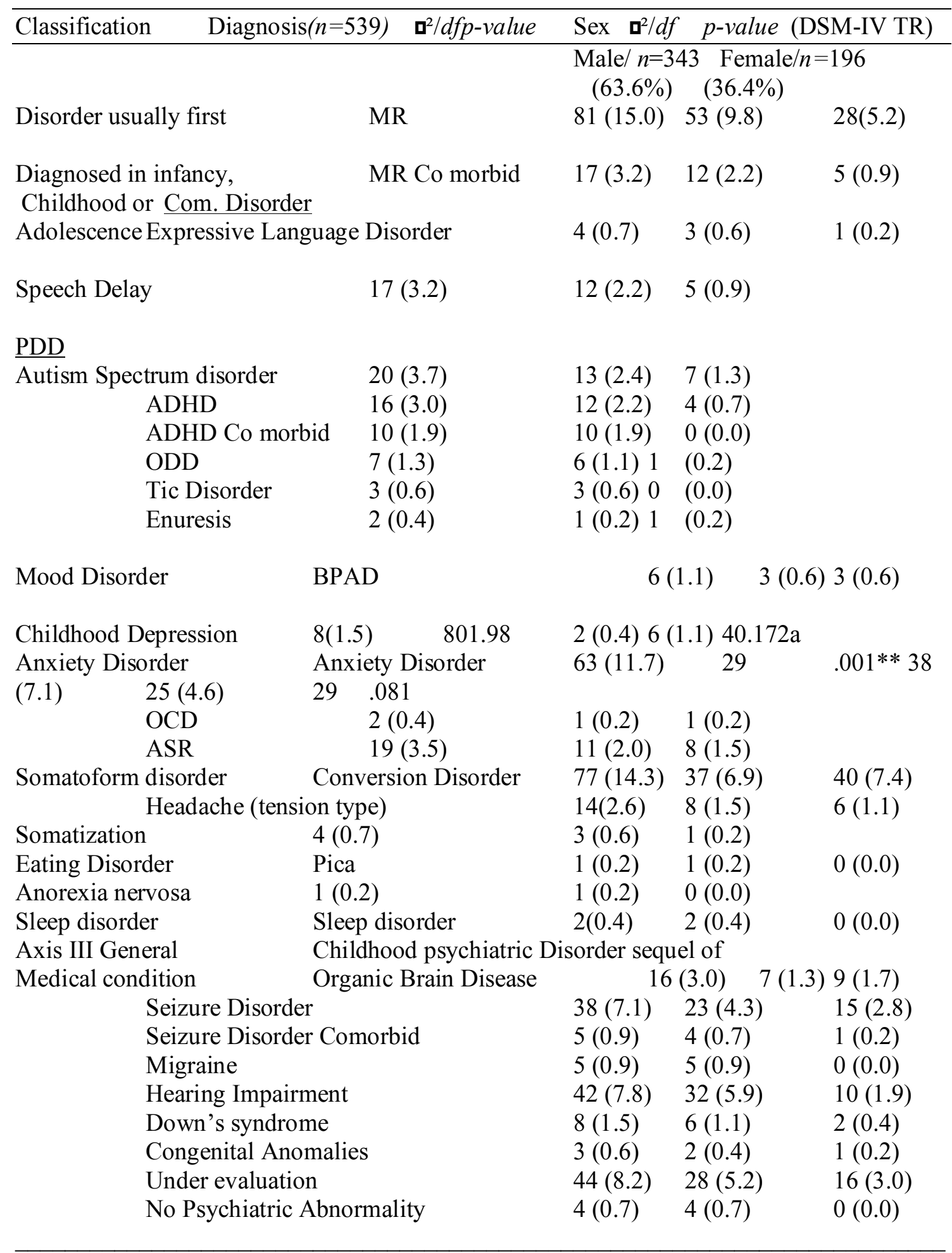

$* * * p<0.001$ 